\title{
Missed dental appointments top 14 million
}

The British Dental Association (BDA) has warned that dentists face an uphill struggle to restore services unless government is willing to support costs for new equipment that could radically expand patient access, as the number of missed appointments hits over 14 million.

Official data on activity seen by the BDA indicates treatments delivered by NHS dental services in England are at a quarter of pre-COVID levels, and have only begun to inch above typical demand for urgent care, which is currently receiving priority. Over 14.5 million fewer treatments have been delivered in 2020 compared to the same period last year.

The 60-minute windows between patients after an aerosol generating procedure (AGP) to minimise risks of viral transmission has contributed to this dramatic fall in patient volumes.
Recent recommendations by the Scottish Dental Clinical Effectiveness Programme $(\text { SDCEP })^{1}$ could reduce this fallow period to as little as ten minutes where dentists can demonstrate a sufficient number of air changes per hour $(\mathrm{ACH})$ in their surgeries.

The BDA has stressed that if practices - both NHS and private - are required to make changes to adhere to new official advice, then government will need to provide financial support.

Progress will require many of the UK's 12,000 practices to undergo an on-site survey by ventilation engineers. With practices already struggling to remain financially sustainable, the BDA has stressed the government must show willingness to underwrite this work and offer commitments for capital funding for necessary equipment.

Practices will likely need mechanical ventilation, fitted internally or externally, with ducting as required, with those with surgeries without natural ventilation, like windows, facing significant challenges. It has been over a decade since dental services in England received any form of direct capital investment. Corporate provider mydentist recently announced a $£ 1.25$ million fund to reduce fallow time to 20 minutes in the 600 practices in their group.

The BDA anticipate many patients with untreated decay will end up requiring more extensive and costly interventions as a result of limited access to dental services. Oral cancers are also going undetected in the absence of routine check-ups.

\section{Reference}

1. Scottish Dental Clinical Effectiveness Programme. Mitigation of Aerosol Generating Procedures in Dentistry - A Rapid Review. 25 September 2020. Available at: https://www.sdcep.org.uk/ published-guidance/covid-19-practice-recovery/ rapid-review-of-agps/ (accessed 24 October 2020). 